\title{
Insights into abdominal pregnancy
}

Gwinyai Masukume

\section{Editor's note}

This article provided a great deal of valuable evidence that was not mentioned in the Wikipedia article on abdominal pregnancy, and the Wikipedia article has subsequently been expanded with text from this publication. However, because of this purpose, it has never been the aim of this article in itself to be a complete review of the subject, and many aspects of abdominal pregnancy are not included herein.

This article also provides an example of how to contribute to Wikimedia projects such as Wikipedia by means of academic publishing.

\section{Introduction}

While rare, abdominal pregnancies have a higher chance of maternal mortality, perinatal mortality and morbidity compared to normal and ectopic pregnancies, but on occasion a healthy viable infant can be delivered. ${ }^{[1]}$

Because tubal, ovarian and broad ligament pregnancies are as difficult to diagnose and treat as abdominal pregnancies, their exclusion from the most common definition of abdominal pregnancy has been debated. ${ }^{[2]}$

Others - in the minority - are of the view that abdominal pregnancy should be defined by a placenta implanted into the peritoneum. ${ }^{[3]}$

\section{Symptoms and signs}

Abdominal pregnancy does not have any specific symptoms and signs so much so that in about half of instances it is missed, only being discovered during surgery; because of the "vague" yet serious nature of the symptoms, signs and results of medical tests patients with abdominal pregnancy will generally have surgery at some point. ${ }^{[4][5][6]}$

Division of Epidemiology and Biostatistics, School of Public Health, Faculty of Health Sciences, University of the Witwatersrand, Johannesburg, South Africa

ORCID: 0000-0002-9251-0264

Corresponding author: parturitions@gmail.com

Licensed under: CC-BY-SA

Received 13-11-2014; accepted 20-11-2014

\section{Risk factors}

Risk factors are similar to tubal pregnancy with sexually transmitted disease playing a major role. ${ }^{[7]}$ However, about half of those with ectopic pregnancy have no known risk factors - known risk factors include damage to the Fallopian tubes from previous surgery or from previous ectopic pregnancy and tobacco smoking. ${ }^{[8]}$

\section{Mechanism}

Typically an abdominal pregnancy is a secondary implantation which means that it originated from a tubal (less common an ovarian) pregnancy and re-implanted. ${ }^{[9]}$ Other mechanisms for secondary abdominal pregnancy include uterine rupture, rupture of a uterine rudimentary horn and fimbrial abortion. ${ }^{[1]}$

\section{Diagnosis}

Suspicion of an abdominal pregnancy is raised when the baby's parts can be easily felt, or the lie is abnormal, the cervix is displaced, or there is failed induction of labor. ${ }^{[4]}$ $\mathrm{X}$-rays can be used to aid diagnosis. ${ }^{[9]}$

To diagnose the rare primary abdominal pregnancy, Studdiford's 1942 criteria need to be fulfilled: tubes and ovaries should be normal, there is no abnormal connection (fistula) between the uterus and the abdominal cavity, and the pregnancy is related solely to the peritoneal surface without signs that there was a tubal pregnancy first. ${ }^{[10]}$ Studdiford's criteria were refined in 1968 


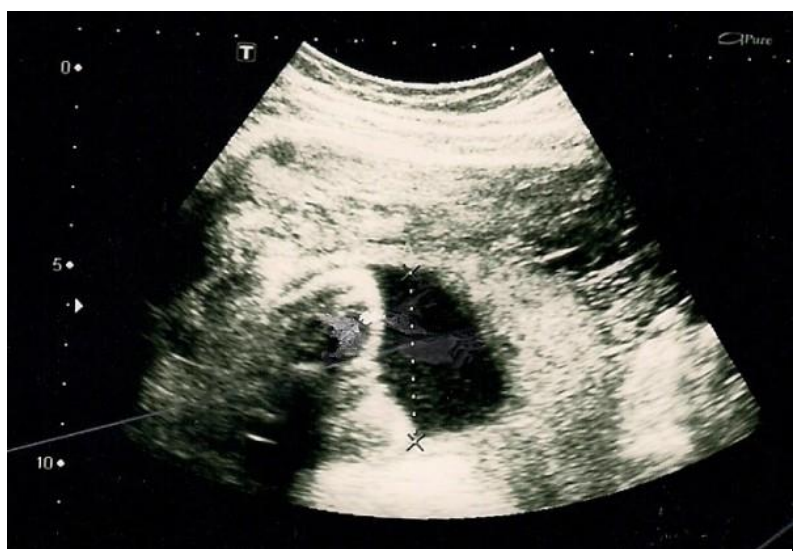

Figure 1 | A 23-week abdominal pregnancy on ultrasound showing a normal fetus and amniotic fluid. Image by Dahab AA, Aburass R, Shawkat W, Babgi R, Essa O, Mujallid RH

by Friedrich and Rankin to include microscopic findings. ${ }^{[11]}$ Keyhole (laparoscopic surgery) can also be used to diagnose abdominal pregnancy. ${ }^{[12]}$

\section{Differential diagnosis}

Depending on gestational age the differential diagnoses for abdominal pregnancy include miscarriage, intrauterine fetal death, placental abruption, an acute abdomen with an intra-uterine pregnancy and a fibroid uterus with an intra-uterine pregnancy. ${ }^{[6]}$

\section{Treatment}

Ideally the management of abdominal pregnancy should be done by a team that has medical personnel from multiple specialties. ${ }^{[13]}$

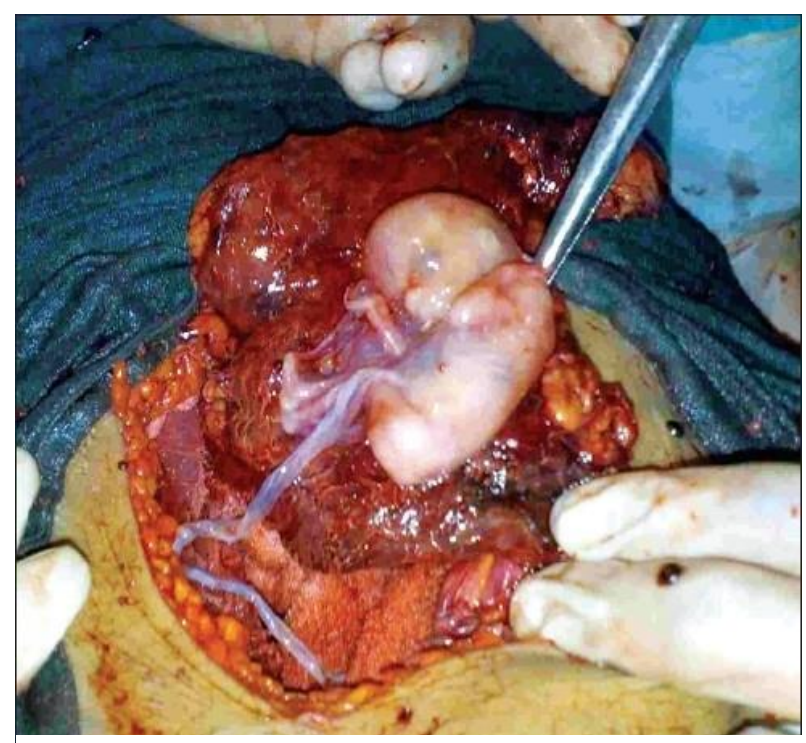

Figure 2 | Abdominal pregnancy being delivered. Image by :Shafi SM, Malla MA, Salaam PA, Kirmani OS
Often, with advancement of the pregnancy the support for the fetus becomes compromised and the fetus dies. ${ }^{[14]} \mathrm{A}$ patient may carry a dead fetus but will not go into labor. Over time, the fetus calcifies and becomes alithopedion. ${ }^{[15]}$

Babies of abdominal pregnancies are prone to birth defects due to compression in the absence of the uterine wall and the often reduced amount of amniotic fluid surrounding the unborn baby. ${ }^{[16]}$

Blood transfusion is frequent in the management of patients with this kind of pregnancy, with others even using tranexamic acid and recombinant factor Vlla, which both minimize blood loss. ${ }^{[4][17]}$

Mifepristone has been used to promote placental regression. ${ }^{[18]}$

Complications of leaving the placenta can include residval bleeding, infection, bowel obstruction, pre-eclampsia (which may all necessitate further surgery) ${ }^{[19][18]}$ and failure to breast feed due to placental hormones. ${ }^{[20]}$

\section{Epidemiology}

Less than $1 \%$ of ectopic pregnancies in the United States are abdominal, or about 1 out of every 10,000 pregnancies. ${ }^{[21]}$ A report from Nigeria places the frequency in that country at 34 per 100,000 deliveries and a report from Zimbabwe, 11 per 100,000 deliveries. ${ }^{[5][22][23]}$ The maternal mortality rate is estimated to be about 5 per 1,000 cases, about seven times the rate for ectopics in general, and about 90 times the rate for a delivery (1987 US data). ${ }^{[21]}$

\section{History}

Albucasis (936-1013), an Arab Muslim physician is credited with first recognizing abdominal pregnancy which was apparently unknown to Greek and Roman physicians and was not mentioned in the writings of Hippocrates; Jacopo Berengario da Carpi (1460-1530) the Italian physician is credited with the first detailed anatomical description of abdominal pregnancy. ${ }^{[24]}$

\section{Natural experiment}

Because pregnancy is outside the uterus, abdominal pregnancy serves as a model of human male pregnancy or for females who lack a uterus, although such pregnancy would be dangerous. ${ }^{[25][26]}$ Abdominal pregnancy has served to further clarify the disease pre-eclampsia 
which was previously thought (1980's) to require a uterus for it to occur, however pre-eclampsia's occurrence in abdominal pregnancy (with the conceptus outside the uterus) helped throw light on pre-eclampsia's etiology. ${ }^{[27]}$ The ratio of live males to females at birth (normal, 107 males to 100 females) ${ }^{[28]}$ is apparently reduced with abdominal pregnancy to as low as 60 males to 100 females (as reported by Masukume) because males are more likely to die in harsh environments (for example in abdominal pregnancy) compared to females. ${ }^{[1]}$

Cases of combined simultaneous abdominal and intrauterine pregnancy have been reported. ${ }^{[18][29]}$

\section{Acknowledgements}

The author would like to thank Dr. James Heilman for his comments and suggestions.

Conflict of Interest: none declared.

\section{References}

1. Masukume G (2014). "Live births resulting from advanced abdominal extrauterine pregnancy, a review of cases reported from 2008 to 2013". WebmedCentral OBSTETRICS AND GYNAECOLOGY 5 (1): WMC004510.

2. Worley, Kevin C.; Hnat, Michael D.; Cunningham, F. Gary (2008). "Advanced extrauterine pregnancy: diagnostic and therapeutic challenges". American Journal of Obstetrics and Gynecology 198 (3): 297.e1-297.e7. doi:10.1016/j.ajog.2007.09.044. ISSN 00029378.

3. Mahajan, Niraj N. (2008). "Advanced extrauterine pregnancy: diagnostic and therapeutic challenges". American Journal of Obstetrics and Gynecology 199 (6): e11. doi:10.1016/j.ajog.2008.06.024. ISSN 00029378.

4. Nkusu Nunyalulendho D, Einterz EM (2008). "Advanced abdominal pregnancy: case report and review of 163 cases reported since 1946". Rural Remote Health 8 (4): 1087. PMID 19053177.

5. Sunday-Adeoye I, Twomey D, Egwuatu EV, Okonta PI (2011). "A 30-year review of advanced abdominal pregnancy at the Mater Misericordiae Hospital, Afikpo, southeastern Nigeria (1976-2006)". Archives of Gynecology and Obstetrics 283(1): 19-24. doi:10.1007/s00404-009-1260-4. PMID 19876640.

6. Oneko, Olola; Petru, Edgar; Masenga, Gileard; Ulrich, Daniela; Obure, Joseph; Zeck, Willibald (2010). "Management of the Placenta in Advanced Abdominal Pregnancies at an East African Tertiary Referral Center". Journal of Women's Health 19 (7): 1369-1375. doi:10.1089/jwh.2009.1704. ISSN 1540-9996.

7. KY Kun, PY Wong, MW Ho, CM Tai, TK Ng (2000). "Abdominal pregnancy presenting as a missed abortion at 16 weeks' gestation". Hong Kong Medical Journal 6 (4): 425-7. PMID 11177167. Retrieved January 25, 2009.

8. Barnhart, Kurt T. (2009). "Ectopic Pregnancy". New England Journal of Medicine 361 (4): 379-387. doi:10.1056/NEJMcp0810384. ISSN 0028-4793.

9. Maurice King, Peter C. Bewes, James Cairns, Jim Thornton (editors). "Primary Surgery; Volume One: Non-trauma. Chapter 8, Abdominal pregnancy". Bonn University. Retrieved 2010-01-25.
10. Studdiford WE (1942). "Primary peritoneal pregnancy". Am J Obstet Gynecol 44: 487-91.

11. Friedrich EG Jr, Rankin CA Jr (1968). "Primary pelvic peritoneal pregnancy". Obstet Gynecol 31 (5): 649-53. PMID 5646396.

12. Torriente, Martin C.; Steinberg, Wilhelm J. (2015). "Abdominal Pregnancy a Report of Two Cases". International Journal of Medical and Pharmaceutical Case Reports 2 (4): 101-105. doi:10.9734/IJMPCR/2015/13995. ISSN 2394-109X.

13. Renfroe, S.; Dajani, N. K.; Pandey, T.; Magann, E. F. (2013). "Role of serial MRI assessment in the management of an abdominal pregnancy". Case Reports 2013 (oct14 1): bcr2013200495-bcr2013200495. doi:10.1136/bcr2013-200495. ISSN 1757-790X.

14. Prajapati, Nilam (2012). "Full-Term Abdominal Pregnancy with Dead Fetus: A Case Report Recipients". Journal of AIDS \& Clinical Research 01 (11). doi:10.4172/scientificreports.434. ISSN 21556113.

15. Medhi, Robin; Nath, Banashree; Mallick, Mangal (2014). "Lithopedion diagnosed during infertility workup: a case report".SpringerPlus 3 (1): 151. doi:10.1186/2193-1801-3-151. ISSN 2193-1801.

16. Stevens CA (1993). "Malformations and deformations in abdominal pregnancy". American Journal of Medical Genetics 47(8): 1189-95. doi:10.1002/ajmg.1320470812. PMID 8291554

17. Dahab, Amal A; Aburass, Rahma; Shawkat, Wasima; Babgi, Reem; Essa, Ola; Mujallid, Razaz H (2011). "Full-term extrauterine abdominal pregnancy: a case report". Journal of Medical Case Reports 5 (1): 531. doi:10.1186/1752-1947-5-531. ISSN 1752-1947.

18. Huang K, Song L, Wang L, Gao Z, Meng Y, Lu Y (2014). "Advanced abdominal pregnancy: an increasingly challenging clinical concern for obstetricians". Int J Clin Exp Pathol 7 (9): 5461-72. PMID 25337188.

19. S. Gibbs, Ronald (2008). Danforth's obstetrics and gynecology (10th ed. ed.). Philadelphia: Lippincott Williams \& Wilkins. p. 84. ISBN 9780781769372

20. Pieh-Holder, Kelly L.; Scardo, James A.; Costello, Deborah H. (2012). "Lactogenesis Failure Following Successful Delivery of Advanced Abdominal Pregnancy". Breastfeeding Medicine 7 (6): 543-546. doi:10.1089/bfm.2011.0131. ISSN 1556-8253.

21. Atrash HK, Friede A, Hogue CJ (1987). "Abdominal pregnancy in the United States: frequency and maternal mortality". Obstet Gynecol 69 (3 Pt 1): 3337. PMID 3822281.

22. White RG (March 1989). "Advanced Abdominal Pregnancy - A Review of 23 Cases". Irish Journal of Medical Science158 (3): 77-8. doi:10.1007/BF02942151. PMID 2753657.

23. Agarwal, Nilesh; Odejinmi, Funlayo (2014). "Early abdominal ectopic pregnancy: challenges, update and review of current management". The Obstetrician \& Gynaecologist 16 (3): 193-198. doi:10.1111/tog.12109. ISSN 14672561.

24. Cotlar AM (2000). "Extrauterine pregnancy: a historical review(3)". Curr Surg 57 (5): 484-492. PMID 11064074.

25. Meryl Rothstein. "Male Pregnancy: A Dangerous Proposition", Popular Science, Bonnier Corporation, 31 July 2005. Retrieved on 12 November 2014.

26. Dick Teresi. "HOW TO GET A MAN PREGNANT", The New York Times, 27 November 1994. Retrieved on 12 November 2014.

27. Moodley J, Subrayen KT, Sankar D, Pitsoe SB (1987). "Advanced extrauterine pregnancy associated with eclampsia. A report of 2 cases.". S Afr Med J 71 (7): 460-1. PMID 3563800.

28. Central Intelligence Agency. "WORLD - Sex ratio", The World Factbook, 2014. Retrieved on 12 November 2014.

29. Zacchè, M.M.; Zacchè, G.; Gaetti, L.; Vignali, M.; Busacca, M. (2011). "Combined intrauterine and abdominal pregnancy following ICSI with delivery of two healthy viable fetuses: a case report". European Journal of Obstetrics \& Gynecology and Reproductive Biology 154 (2): 232-233. doi:10.1016/j.ejogrb.2010.10.015. ISSN 03012115. 